\title{
Chloro-benzoquinones cause oxidative DNA damage through iron-mediated ROS production in Escherichia coli
}

\author{
Zhilan Chen ${ }^{\mathrm{a}, \mathrm{b}}$, Qiaohong Zhou ${ }^{\mathrm{a}, *}$, Dandan Zou ${ }^{\mathrm{b}, \mathrm{c}}$, Yun Tian ${ }^{\mathrm{a}, \mathrm{c}}$, Biyun Liu ${ }^{\mathrm{a}, *}$, Yongyuan Zhang ${ }^{\mathrm{a}}$, \\ Zhenbin $\mathrm{Wu}^{\text {a }}$ \\ a State Key Laboratory of Freshwater Ecology and Biotechnology, Institute of Hydrobiology, Chinese Academy of Sciences, Donghu South Road 7, Wuhan 430072, China \\ ${ }^{\mathrm{b}}$ State Key Laboratory of Environmental Chemistry and Ecotoxicology, Research Center for Eco-Environmental Sciences, Chinese Academy of Sciences, Shuangqing Road 18, \\ Beijing 100085, China \\ ${ }^{\mathrm{C}}$ University of Chinese Academy of Sciences, 19A Yuquan Road, Beijing 100049, China
}

\section{H I G H L I G H T S}

- CBQs have genotoxicity and cytotoxicity in E. coli cells.

- CBQs exposure to E. coli cells led to intracellular substantial ROS production.

- The addition of $\mathrm{Fe}^{2+}$ to the CBQs exposure system enhanced DNA oxidative damage.

- ROS scavengers and iron-chelators can partial protect from oxidative DNA damage.

- AhpCF, catalase E and catalase G protected E. coli from DNA damage corporately.

\section{A R T I C L E I N F O}

\section{Article history:}

Received 30 December 2014

Received in revised form 13 April 2015

Accepted 24 April 2015

Available online 18 May 2015

\section{Keywords:}

Chloro-benzoquinones

Oxidative DNA damage

Iron ion

ROS

E. coli ahpCF katEG mutants

\begin{abstract}
A B S T R A C T
Chloro-benzoquinones (CBQs) are a group of disinfection byproducts that are suspected to be potentially carcinogenic. Here, the mechanism of DNA damage caused by CBQs in the presence of ferrous ions was investigated in an Escherichia coli wild type M5 strain and a mutant L5 (ahpCF katEG mutant) strain that carried an enhanced green fluorescent protein reporter under the control of a SOS response gene ( $r e c A$ ) promoter. All tested CBQs (including para-benzoquinone, 2-chloro-para-benzoquinone, and dichloro-para-benzoquinones with different substitutes) caused substantial oxidative DNA damage with $E C_{50}$ values in the micromolar range. Moreover, 2,5-dichloro-para-benzoquinone (2,5-DCBQ), a typical $\mathrm{CBQ}$, caused substantial ROS production in E. coli mutant cells. And ROS scavengers provided partial protective effects on genotoxicity of 2,5-DCBQ to E. coli mutant cells. The addition of $\mathrm{Fe}^{2+}$ to the 2,5-DCBQ exposure system caused an increase in DNA oxidative damage; iron-chelating agents could partially prevent these cells from DNA damage. Finally, intracellular AhpCF, catalase E, and catalase G were all found to play an important role in the survival of $E$. coli cells exposed to CBQs, as indicated by an increased sensitivity of the ahpCF katEG mutant L5 strain to treatment compared with wild type M5 cells. Taken together, these results suggest that CBQs cause oxidative DNA damage in E. coli cells through the participation of iron-mediated ROS production.
\end{abstract}

(c) 2015 Elsevier Ltd. All rights reserved.
Abbreviations: CBQs, chloro-benzoquinones; HBQs, halogenated benzoquinones; DCBQ dichloro-para-benzoquinones; $\mathrm{DCMBQ}$ dichloromethylbenzoquinone; TriCBQ trichloro-para-benzoquinone; DBBQ dibromo-para-benzoquinone; OH-HBQs, OH-halobenzoquinones; AhpCF, alky hydroperoxide reductase; DMDBBQ 2,3-dibromo-5,6-dimethyl-(1,4)benzoqui none; $\mathrm{NADH}$, nicotinamide adenine dinucleotide; ROS, reactive oxygen species; $\mathrm{BQ}$ para-benzoquinone; 2-CBQ 2-chloro-para-benzoquinone; 2,3-DCBQ 2,3-dichloro-para-benzoquinone; 2,5-DCBQ 2,5-dichloro-para-benzoquinone; 2,6-DCBQ 2,6-dichloro-para-benzoquinone; DFO, deferoxamine; DIP, 2,2'-dipyridine; PHEN, o-phenanthroline; DHE, dihydroethidium; DCFH-DA, 2',7'dichlorodihydrofluorescein diacetate; $O D$, optic density; $F_{i}$, induction factor; $S F U$, specific fluorescence unit; $t$-BuOOH, tert-Butylhydroperoxide; $\mathrm{CuOOH}$, cumene hydroperoxide; 8-oxodG, 8-oxo-7,8-dihydro-2'-deoxyguanosine.

* Corresponding authors.

E-mail addresses: qhzhou@ihb.ac.cn (Q. Zhou), liuby@ihb.ac.cn (B. Liu).

\section{Introduction}

Humans can be chronically exposed to halogenated benzoquinones (HBQs) created during the chlorine- and chloramine-disinfection process of phenol-like matrix chemicals (Heasley et al., 2004). HBQs can also be metabolized in vivo (Chignell et al., 2008) or dechlorinated chemically from polyhalogenated aromatic compounds, such as polychlorophenol, brominated flame retardants, hexachlorobenzene, and Agent Orange (Song et al., 2008; Meunier, 2002; Gupta et al., 2002; Sorokin et al., 1995). The production process of HBQs may result in the carcinogenesis of these polyhalogenated aromatic compounds (Zhu, 
2009), however, no direct experimental data of HBQ-related carcinogenesis has yet been published. Nonetheless, a possible role of HBQ in bladder cancer has been proposed through quantitative structure-toxicity relationship analyses (Bull et al., 2006).

In fact, four different kinds of HBQs as chlorination disinfection byproducts in drinking water were initially discovered, including dichloro-para-benzoquinone (DCBQ), dichloromethylbenzoquinone (DCMBQ), trichloro-para-benzoquinone (TriCBQ), and dibromo-para-benzoquinone (DBBQ) (concentrations: 0.5$165 \mathrm{ng} / \mathrm{L}$ ), among which DCBQ was the most easily formed chemical with the highest concentrations (Zhao et al., 2010). In subsequent investigations, as many as 12 kinds of HBQs in drinking water were found at ng/L levels (Huang et al., 2013). Similarly, UV irradiation use in water treatment plants can induce the transformation of HBQs to OH-halobenzoquinones (OH-HBQs), which can then be further modified into mono-halogenated benzoquinones (Qian et al., 2013). Moreover, specific conditions, such as elevated dissolved organic carbon, in addition to chlorine, higher temperatures, and personal care products can promote the formation of HBQs (TriCBQ, DMDBBQ and 2,6-DBBQ) in swimming pools originally absent in the input water; in fact, the concentration of 2,6-DCBQ has been found to be as high as 100 times that of the input water (Wang et al., 2013). Taken together, these findings indicate that chloro-benzoquinones (CBQs) are important HBQs that have the potential to impact humans via multiple pathways.

Previously, hydroxyl radicals were found to be formed through transition metal copper-mediated Fenton reactions in vitro and to cause oxidative DNA damage (Gunther et al., 1995; Lloyd and Phillips, 1999). In addition, copper ions could efficiently mediate any DNA damage caused by DCBQs in the presence of NADH, in vitro (Oikawa and Kawanishi, 1996). However, intracellular copper cannot cause oxidative DNA damage in Escherichia coli cells because of its low intracellular concentration and inactivation by its ligation to thiols (Imlay, 2003; Macomber et al., 2007). Another transition metal, iron, also participates in both the oxidative DNA damage process seen in vitro (Lloyd and Phillips, 1999; Henle et al., 1996) and in Fenton-like reactions in E. coli cells (Imlay, 2003; Mccormick et al., 1998). It has not been proven if iron ions can participate in oxidative DNA damage caused by chloro-benzoquinones in E. coli cells.

An SOS protein, RecA, can be induced by oxidative stress in E. coli cells (Van Bogelen et al., 1987; Greenberg and Demple, 1989). Previously, we utilized the enhanced green fluorescent protein as a reporter under the control of the recA promoter to construct a pET16b-derived plasmid, pETPrecAegfp5 (Chen et al., 2012). The resultant E. coli L5 strain (E. coli LC106 strain with ahpCF katEG mutants carrying the pETPrecAegfp5 plasmid) is able to detect oxidatively DNA damaging agents with a sensitivity at least 10-20 times greater than that of other bacterial biosensors, demonstrating an incomparable superiority for investigating the mechanism of DNA damage caused by oxidative chemicals (Chen et al., 2011).

In this study, we utilized the E. coli katEG aphCF strains to evaluate the oxidative DNA damage and intracellular reactive oxygen species (ROS) level caused by CBQs. Moreover, we also investigated the functions of iron ions, iron chelators, ROS scavengers, and antioxidative enzymes (including alkyl hydroperoxide reductase, catalase $\mathrm{E}$, and catalase $\mathrm{G}$ ) in the process of oxidative damage.

\section{Material and methods}

\subsection{Chemicals}

Para-benzoquinone (BQ), 2-chloro-para-benzoquinone (2-CBQ), 2,3-dichloro-para-benzoquinone (2,3-DCBQ), 2,5-dichloro-para- benzoquinone (2,5-DCBQ), 2,6-dichloro-para-benzoquinone (2,6DCBQ), deferoxamine (DFO), 2,2'-dipyridine (DIP), and o-phenanthroline (PHEN) were purchased from Sigma (USA) and used without further purification. Fluorescent probes including dihydroethidium (DHE) and 2',7'-dichlorodihydrofluorescein diacetate (DCFH-DA), ROS scavengers including mannitol, benzoate, and ascorbic acid were purchased from Sigma (USA). Chemically pure $\mathrm{H}_{2} \mathrm{O}_{2}$ and $\mathrm{FeSO}_{4}$ were purchased from Beijing Chemical Works, China.

\subsection{Bacterial strains and cultivation conditions}

The E. coli LC106 strain (katEG aphCF in MG1655) was inoculated into fresh GCTM medium $(0.2 \%(\mathrm{~W} / \mathrm{V})$ glucose, $0.2 \%(\mathrm{~W} / \mathrm{V})$ casein acidic hydrolysate, $0.2 \mathrm{mM}$ tryptophan, $5 \mu \mathrm{g} / \mathrm{mL}$ thiamine, and M9 salts (Sambrook and Russell, 2001)) and modified slightly (Park et al., 2005). The E. coli L5 strain was inoculated in fresh GCTMA medium (GCTM medium added $60 \mu \mathrm{g} / \mathrm{mL}$ ampicillin). Anaerobic cultivation of the E. coli cells was performed at $37^{\circ} \mathrm{C}$, without shaking, in fresh anaerobic medium until log phase $\left(O D_{600} \sim 0.15\right)$ in MGC AnaeroPack ${ }^{\mathrm{TM}}$ Series bag (Mitsubishi, Japan) in a YQX-II Anaerobic Chamber (Xinmiao Medical Instrument Co., Lmt., Shanghai, China). Both the LC106 strain and its derivative L5 strain were cultivated anaerobically until log phase. The wild type E. coli MG1655 strain and the M5 strain (the MG1655 strain carrying the pETPrecAegfp5 plasmid) were cultured in fresh GCTM medium and GCTMA medium aerobically, respectively.

\subsection{Chemical induction}

The L5 strain was anaerobically grown in the GCTMA medium at $37^{\circ} \mathrm{C}$ overnight and inoculated into fresh GCTMA medium at a $1: 50$ ratio and grown to $\log$ phase $\left(O D_{600} \sim 0.15\right)$. All aerobic exposure protocols were conducted in the same way as done previously (Chen et al., 2011). The treatment of a series of different CBQs concentrations $(0,0.1,1,10,50$ and $100 \mu \mathrm{M})$ was performed to $\log$ phase cells at $37{ }^{\circ} \mathrm{C}$ for $2 \mathrm{~h}$ at $130 \mathrm{rpm}$. Ferrous ion or ROS scavengers or iron chelators were mixed with 2,5-DCBQ before the treatment of L5 cells. Exposure with mixture was also performed at $37{ }^{\circ} \mathrm{C}$ for $2 \mathrm{~h}$ at $130 \mathrm{rpm}$. The treatment concentrations were as follows: 2,5 -DCBQ $(0,1,10,20,50,75,100 \mu \mathrm{M})$, ferrous ion $(0,5,25,50 \mu \mathrm{M})$, mannitol and benzoate $(0,1,10,50$, $100 \mathrm{mM})$, ascorbic acid $(0,1,5,10,20 \mathrm{mM})$, DFO and PHEN (2 $\mathrm{mM})$, DIP $(1 \mathrm{mM})$. The anaerobic exposure was performed in a 96 -well plate (Corning, USA) with $20 \mu \mathrm{L}$ of chemicals in aqueous solution and $180 \mu \mathrm{L}$ bacterial culture per well in MGC AnaeroPack ${ }^{\mathrm{TM}}$ Series bag (Mitsubishi, Japan) and shaken manually several times for uniformity. Induction was carried out at $37^{\circ} \mathrm{C}$ in the time in the Anaerobic Chamber. Untreated L5 cells were added with $20 \mu \mathrm{L}$ of sterile water as the control. The blank LC106 strain was anaerobically grown in GCTM medium to log phase; $20 \mu \mathrm{L}$ of sterile water was added during the induction process to zero the auto-fluorescence emission of the E. coli cells. The M5 and MG1655 strains were aerobically grown to log phase; the induction protocols were the same as the L5 and LC106 strains.

\subsection{Fluorescent microscopy analysis}

Fluorescent microscopy analysis was performed as described previously (Chen et al., 2012). Fluorescence images of bacterial cells were obtained by confocal laser scanning microscope consisting of a Leica DMI 6000B inverted microscope $(100 \times$ oil immersion objective, 1.40 numerical aperture NA) and a Leica TCS SP5 
confocal scanning system. The fluorescence of $E$. coli cells were excited by the $488 \mathrm{~nm}$ line of an argon ion laser $(4.5 \mathrm{~mW})$, and emission was detected by a photomultiplier tube (PMT) at 500$560 \mathrm{~nm}$; the PMT voltage was set at $890 \mathrm{~V}$. Bright-field images were acquired with a PMT gain of $340 \mathrm{~V}$. Each image was taken from a physical dimension of $155 \mu \mathrm{m} \times 155 \mu \mathrm{m}$.

\subsection{Flow cytometry analysis}

For a bivariate side scatter (SSC) vs. forward scatter (FSC) analysis, L5 strain cells under the exposure of 2,5-DCBQ performed as described in Section 2.3 with 10,000 counts were analyzed via flow cytometry (FACSAria ${ }^{\mathrm{TM}}$ III, BD Co., US). For intracellular ROS level detection, DHE $(10 \mu \mathrm{M})$ and DCFH-DA $(20 \mu \mathrm{M})$ were incubated with the log phase LC106 strain cells for $30 \mathrm{~min}$ at $37^{\circ} \mathrm{C}$. Then, serial concentrations of 2,5-DCBQ were added to the culture, which would be shaken at $130 \mathrm{rpm}$ for $2 \mathrm{~h}$ at $37^{\circ} \mathrm{C}$. LC106 strain cells with 10,000 counts were analyzed via flow cytometry (FACSAria $^{\mathrm{TM}}$ III, BD Co., US) with an excitation of $488 \mathrm{~nm}$ and an emission of $610 \mathrm{~nm}$ (for DHE) and $525 \mathrm{~nm}$ (for DCFH-DA). Data were analyzed through FACSDiva Version 6.1.3.

\subsection{Fluorescence spectral scanning and optic density detection}

Fluorescence scanning and optic density $(O D)$ value detection of the aerobic induction were performed as previously reported (Chen et al., 2011). E. coli cells were excited at $480 \mathrm{~nm}$, and the fluorescence was scanned from 500 to $600 \mathrm{~nm}$ in the 96-well plate (Corning, USA) with the spectral scanning multimode reader (Varioskan Flash, Thermo). The cell density $\left(O D_{600}\right)$ was determined simultaneously using the same device. Data for these detections were recorded by SkanIt Software 2.4.3 RE for Varioskan ${ }^{\circledR}$ Flash.

\subsection{Data analysis}

The induction factor $\left(F_{i}\right)$ and $O D_{x} / O D_{0}$ value were measured as previously reported (Chen et al., 2011). The specific fluorescence unit $(S F U)$ value indicates the value of the detected fluorescence intensity divided by the optical density of $E$. coli cells at $600 \mathrm{~nm}$ $\left(O D_{600}\right)$. The absolute $S F U$ value indicates the $S F U$ value of the treated sample minus that of the control strain. The induction factor was calculated by the absolute $S F U$ value at $509 \mathrm{~nm}$ of the treated sample divided by the absolute $S F U$ value of the untreated sample (Chen et al., 2011). The $E C_{50}$ values were calculated as the concentrations of tested compounds causing a $50 \%$ decrease in the survival of the target organism; when the $O D_{x} / O D_{0}$ value of the tested compounds equaled 0.5 , the exact concentration was deemed to be the $E C_{50}$ value of this compound. The protection effect of the ROS scavengers (\%) was equal to $\left[1-\left(S F U_{C R} / S F U_{C}\right)\right] \times 100 \%$, where: $S F U_{C R}$ was the $S F U$ value of the L5 strain cells exposed to CBQ-ROS scavengers, and $S F U_{C}$ was the $S F U$ value of the $\mathrm{L} 5$ strain cells exposed to $\mathrm{CBQ}$. The DNA damage increment rate (\%) was equal to $\left[\left(S F U_{C R F} / S F U_{C R}\right)-1\right] \times 100 \%$, where: $S F U_{C R F}$ was the $S F U$ value of the L5 strain cells exposed to CBQ-ROS scavengers-Fe ${ }^{2+}$ and $S F U_{C R}$ was the $S F U$ value of the L5 strain cells exposed to CBQ-ROS scavengers.

Experiments were performed at least three times, and the standard deviations between the experiments were determined. Statistical analyses were carried out using One-way ANOVA with Tukey's test with the aid of Origin 7.0 software.

\section{Results}

\subsection{CBQs cause oxidative DNA damage to the $L 5$ strain cells}

CBQs (including BQ, 2-CBQ, 2,3-DCBQ, 2,5-DCBQ and 2,6-DCBQ) caused oxidative DNA damage in a dose-dependent manner in the L5 strain cells $(0.1-100 \mu \mathrm{M})$ ( Fig. 1). When $25 \mu \mathrm{M} \mathrm{H}_{2} \mathrm{O}_{2}$ was added, the level of oxidative DNA damage increased slightly, as compared to L5 strain cells treated only with CBQs, except those exposed with two chlorine-substitution BQs at a concentration of $100 \mu \mathrm{M}$ (Fig. 1). CBQs caused genotoxicity and cytotoxicity in the $\mathrm{L} 5$ strain cells; the $E C_{50}$ values of the $\mathrm{CBQs}$ were in order of: $\quad \mathrm{BQ}<2,3-\mathrm{DCBQ}<2,6-\mathrm{DCBQ}<2,5-\mathrm{DCBQ}<2-\mathrm{CBQ}$ (Table 1). Moreover, as compared to both the $\mathrm{CBQ}$ system by itself and the $\mathrm{CBQ}+\mathrm{H}_{2} \mathrm{O}_{2}$ system, the 2,3-DCBQ $+\mathrm{H}_{2} \mathrm{O}_{2}$ system exhibited the highest $\triangle E C_{50}$ value (Table 1 ).

The green fluorescence intensity of $E$. coli L5 cells indicated the level of oxidative DNA damage, while the cell density in bright field images indicated cell viability. As seen in Fig. 2, the E. coli L5 strain was highly sensitive to oxygen and clearly demonstrated a higher level of DNA damage than that of anaerobic condition (Fig. 2A and B). Whether under anaerobic or aerobic conditions, the L5 strain cells exposed to 2,5-DCBQ displayed substantial oxidative DNA damage and a large scale of cell death (Fig. 2E-H). Under aerobic conditions, the L5 strain cells exposed to 2,5-DCBQ displayed a significant increase in DNA damage as opposed to L5 strain cells without 2,5-DCBQ exposure (Fig. 2B and F). In addition, during the process of oxidative DNA damage caused by the exposure to 2,5-DCBQ the E. coli L5 strain cells were larger and exhibited a damaged cell structure (Fig. 2I and J).

\subsection{Intracellular ROS plays an important role}

DCFH-DA was used as a fluorescent probe to detect the intracellular $\mathrm{OH}^{\cdot}$ and $\mathrm{H}_{2} \mathrm{O}_{2}$ level while DHE was used to detect intracellular superoxide anions $\left(\mathrm{O}_{2}^{-}\right)$. To avoid the interference of green fluorescence to DCF, a LC106 strain lacking EGFP expression was used as the target strain in the detection of intracellular ROS level. Results showed that the fluorescent intensity of DCF and ethidium (the oxidative product of DCFH-DA and DHE respectively) significantly increased with increasing concentrations of 2,5-DCBQ exposure concentration $(p<0.01)$ (Fig. 3A). We found a similar dose-ROS level effect when the LC106 strain was exposed to other CBQs (data not shown). When ROS scavengers, such as mannitol, benzoate, and ascorbic acid, were added into the L5 + 2,5-DCBQ $(75 \mu \mathrm{M})$ exposure system, the oxidative DNA damage statistically decreased as compared with the L5 +2,5-DCBQ exposure system (Fig. 3B). In addition, the ability of mannitol, benzoate, and ascorbic acid to prevent oxidative DNA damage was considered to be $31.4-37.3 \%$, $27.3-42.5 \%$, and $28.4-39.7 \%$, respectively. These results demonstrate that the intracellular ROS yielded from 2,5-DCBQ exposure participates in the process of oxidative DNA damage in the mutant cells.

\subsection{Iron ions participate in the process of oxidative DNA damage}

\subsubsection{The effect of iron ions on CBQ toxicity in the L5 strain cells}

Whether 2,5-DCBQ was added or not, the level of oxidative DNA damage of the L5 strain cells significantly increased with rising concentrations of iron ions $(p<0.01)$ (Fig. 4A). When ferrous ions $(50 \mu \mathrm{M})$ were added to the ROS scavenger $+2,5$-DCBQ system, the oxidative DNA damage of the L5 strain cells was higher than that of the ROS scavenger + 2,5-DCBQ system (Fig. 4B). 

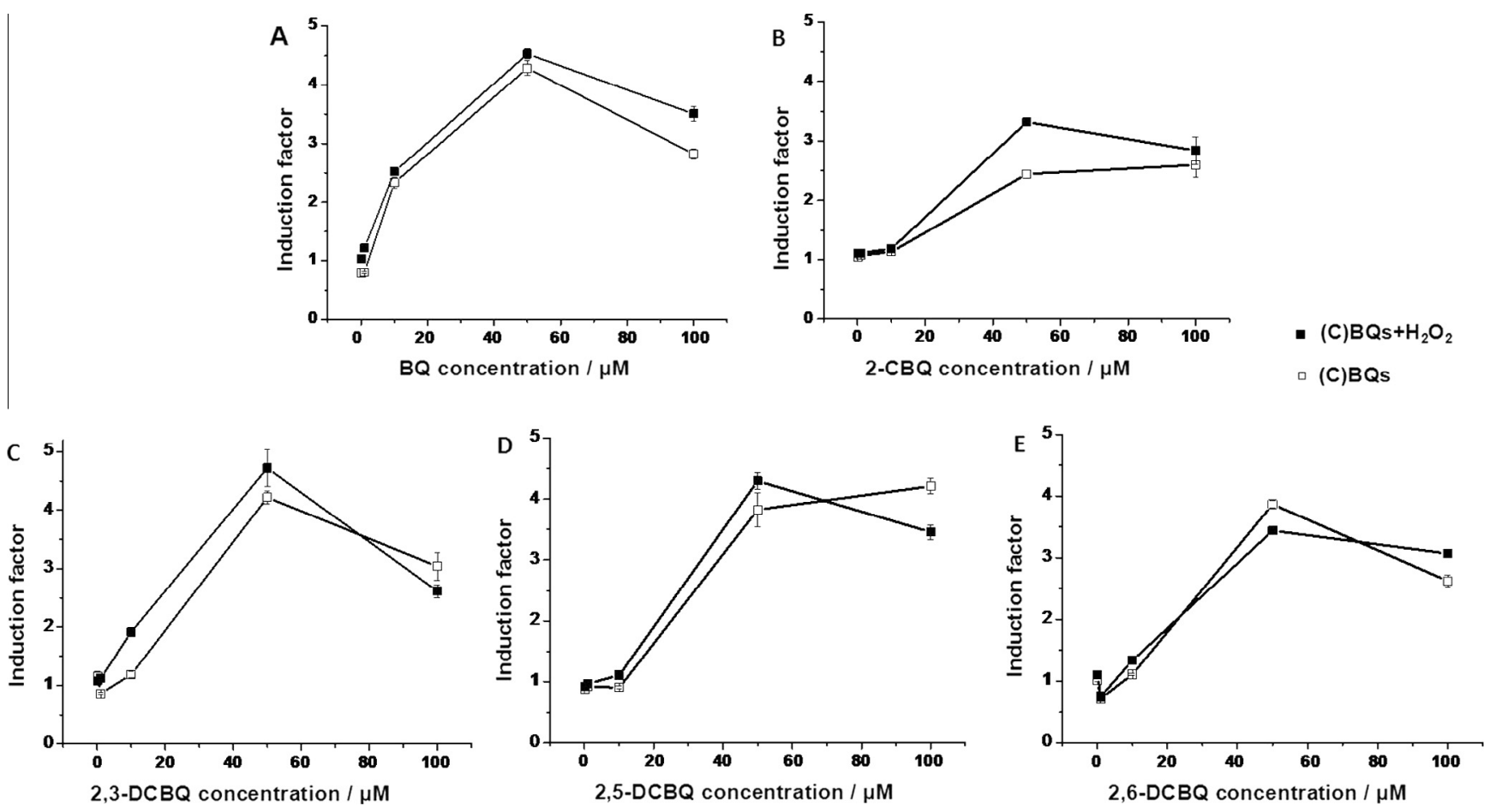

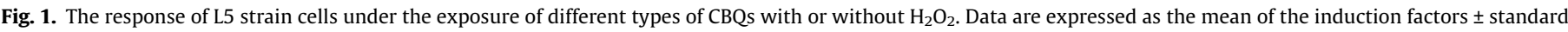
deviation.

Table 1

The $E C_{50}$ values of CBQs in the $\mathrm{L} 5$ strain cells with or without $\mathrm{H}_{2} \mathrm{O}_{2}(\mu \mathrm{M}){ }^{1}$

\begin{tabular}{lccr}
\hline $\mathrm{CBQ} s$ & None addition & \multicolumn{1}{c}{$+\mathrm{H}_{2} \mathrm{O}_{2}$} & $\Delta E C_{50}$ \\
\hline $\mathrm{BQ}$ & $9.56 \pm 0.48$ & $7.27 \pm 0.36^{* *}$ & 2.29 \\
$2-\mathrm{CBQ}$ & $41.98 \pm 2.10$ & $35.48 \pm 1.77^{*}$ & 6.51 \\
$2,3-\mathrm{DCBQ}$ & $32.27 \pm 1.61$ & $15.80 \pm 0.79^{* *}$ & 16.47 \\
$2,5-\mathrm{DCBQ}$ & $37.48 \pm 1.87$ & $29.22 \pm 1.46^{* *}$ & 8.26 \\
$2,6-\mathrm{DCBQ}$ & $35.09 \pm 1.75$ & $28.07 \pm 1.40^{* *}$ & 7.02 \\
\hline
\end{tabular}

The $E C_{50}$ values of L5 strain cells exposed to CBQs with or without $\mathrm{H}_{2} \mathrm{O}_{2}(25 \mu \mathrm{M})$.

${ }^{1}$ Values in the same line are significantly different as analyzed by Tukey's test $\left({ }^{* *} p<0.01,{ }^{*} p<0.05\right)$.

\subsubsection{The effect of iron chelators on the CBQ toxicity}

Three iron-chelators (DFO, DIP, and PHEN) were used to identify the function of iron in the process of oxidative DNA damage in the L5 strain cells. The addition of iron-chelators to the 2,5-DCBQ exposure system significantly decreased the levels of oxidative DNA damage in the L5 strain as compared to those with 2,5 -DCBQ exposure only $(p<0.01)$. Furthermore, whether adding the $\mathrm{Fe}^{3+}$-chelating agent DFO or the $\mathrm{Fe}^{2+}$-chelating agents DIP and PHEN, the cell survival range of the L5 strain exposed to 2,5 -DCBQ was statistically increased $(p<0.01)$ (Table 2 ).

3.4. Catalase E, catalase $G$, and alkyl hydroperoxide reductase defend together against oxidative DNA damage by $C B Q s$

We found that the deletion of key antioxidant enzymes (alkyl hydroperoxide reductase (Ahp), catalase G, and catalase E) in the L5 strain allowed for micromolar levels of 2,5-DCBQ to cause substantial oxidative DNA damage. Concentrations as high as $75 \mu \mathrm{M}$ 2,5-DCBQ failed to cause significant oxidative DNA damage in the wild type E. coli M5 strain cells (Fig. 5A). Simultaneously, the wild type M5 strain cells had a higher survival rate as compared to that of the L5 strain cells (Fig. 5B). This phenomenon indicated that Ahp, catalase G, and catalase E provide a partial, but significant, protection against $\mathrm{CBQ}$-induced oxidative DNA damage in $E$. coli cells.

\section{Discussion}

Bladder cancer has been associated with long-term exposure to disinfection by-products (DBPs) in drinking water (Cantor et al., 1998; King and Marrett, 1996; McGeehin et al., 1993; Villanueva et al., 2004). There was no direct proof, which demonstrated CBQs as a kind of DBPs were related bladder carcinogenicity in humans. E. coli, a model bacterial species, cannot degrade CBQs (McCarthy et al., 1997), was invoked as the target organism for the possible damage mechanism of $\mathrm{CBQs}$ to biological cells. And we confirmed that CBQs can cause oxidative DNA damage and cell death in a dose-dependent manner in E. coli cells. These results are consistent in mammalian cells (Du et al., 2013). The bacterial test system with CBQs exposure is sensitive, rapid and low-cost contrast with the expensive and long-term animal experiments. To our knowledge, CBQs have not been shown to be genotoxic in bacterial test systems except our mutant E. coli strains (Chen et al., 2011).

The cytotoxicity rank order of tested CBQs in E. coli L5 cells confirmed that $\mathrm{BQ}$ was more toxic to Gram-negative bacteria compared to chlorine-substituted para-benzoquinones (Beckman and Siedow, 1985). In addition, the higher $\triangle E C_{50}$ value of 2,3-DCBQ indicated that $\mathrm{H}_{2} \mathrm{O}_{2}$, or the intracellular oxidative potential, likely has a more significant effect on the toxicity of 2,3-DCBQ than the other CBQs. Similarly, in a metal-free system, 2,3-DCBQ $+\mathrm{H}_{2} \mathrm{O}_{2}$ was found to have the largest effect on oxidizing calf thymus DNA to form 8-oxodG (Yin et al., 2013). Taken together, these data demonstrate the importance of 2,3-DCBQ $+\mathrm{H}_{2} \mathrm{O}_{2}$ and help to partially validate our results, in vitro.

Iron ions play an important role in the formation of oxidative DNA damage exposed to $\mathrm{H}_{2} \mathrm{O}_{2}$ in $E$. coli cells (Imlay, 2003; Mccormick et al., 1998). However, the effect of iron ions on CBQ-induced toxicity of $E$. coli cells is unknown. Results also 

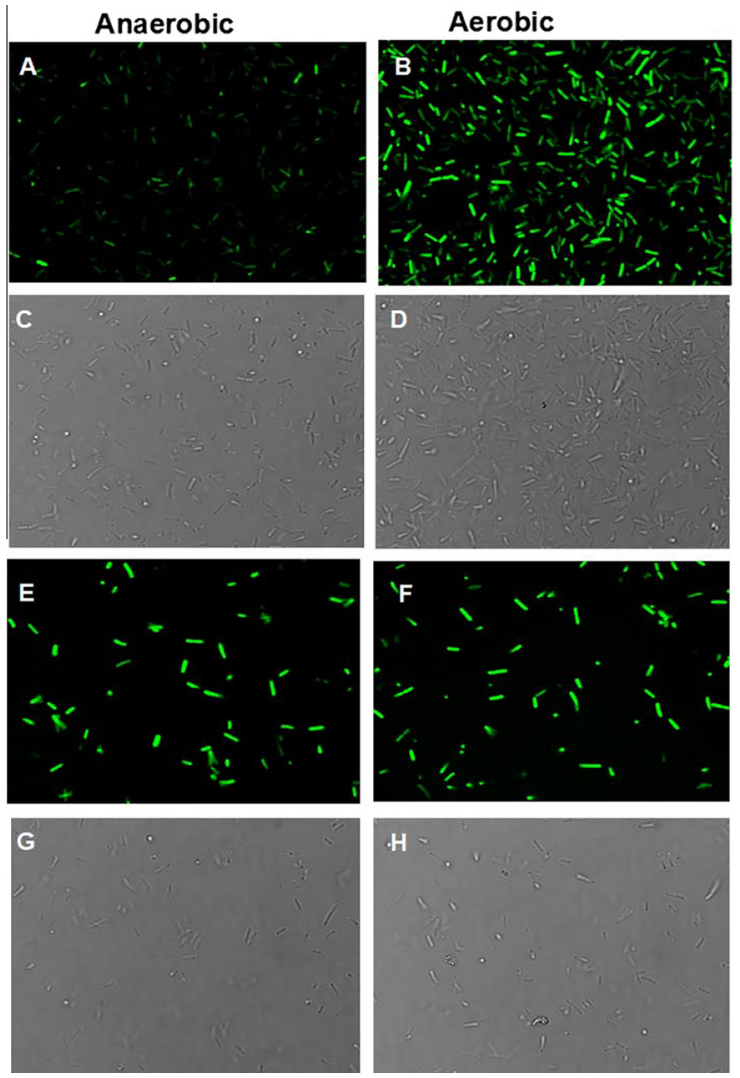
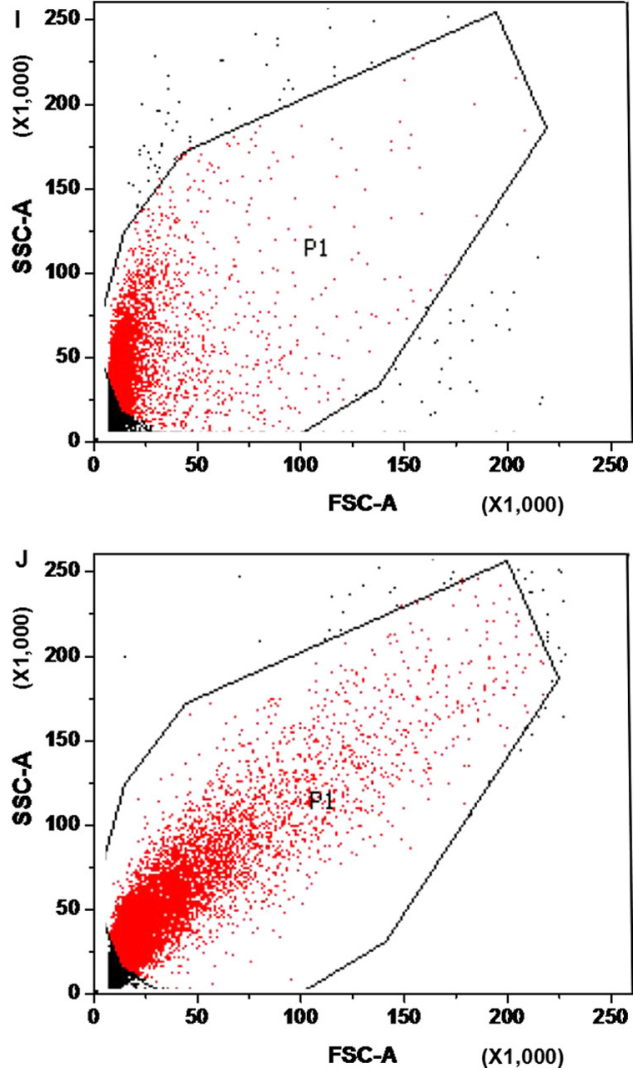

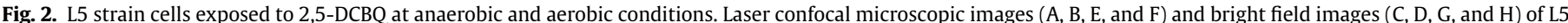

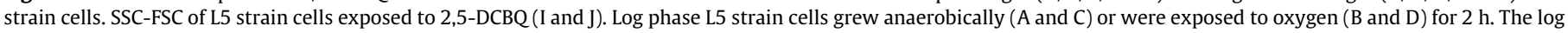

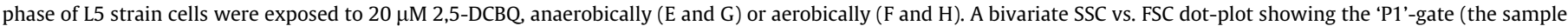
shown is the L5 strain cells with $0 \mu \mathrm{M}$ 2,5-DCBQ exposure) (I). SSC vs. FSC of L5 strain cells exposed to 100 $\mu \mathrm{M} 2,5-\mathrm{DCBQ}$ (J).
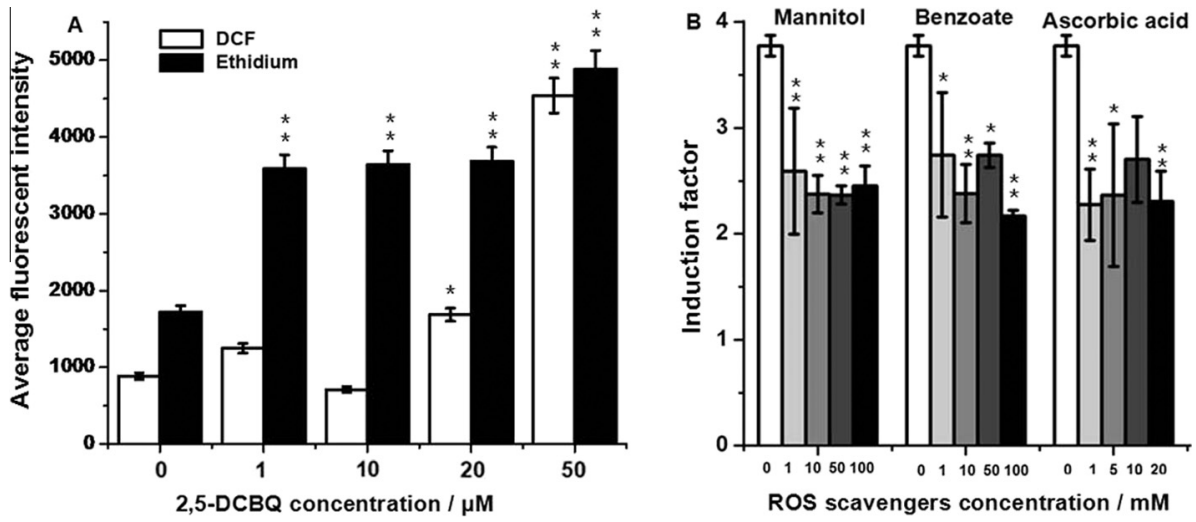

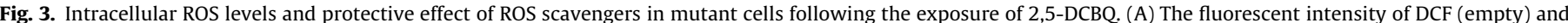

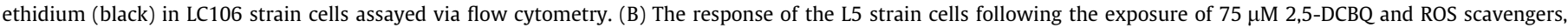

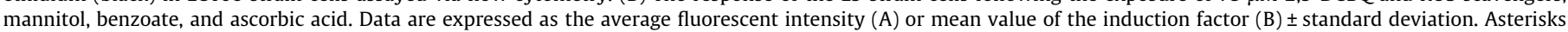
indicate statistical differences between treatments and control. ${ }^{*} p<0.05 ;{ }^{* *} p<0.01$.

revealed that the $\mathrm{CBQ}$ toxicity is a function of the presence of iron ions in the $E$. coli mutant cells. The addition of iron significantly enhanced the oxidative DNA damage potential of CBQs. The administration of iron chelators (DFO, DIP, and PHEN) resulted in a significant protection from oxidative DNA damage and bacterial death. ROS production also increased with increasing CBQ exposure, while the addition of ROS scavengers (the $\mathrm{OH}$ scavengers, mannitol and benzoate, and the aqueous ROS scavenger, ascorbic acid) significantly protected the cells against oxidative DNA damage; the addition of extra iron in the CBQ + ROS scavenger system led to enhancing oxidative DNA damage. Moreover, antioxidative enzymes (including Ahp, catalase $\mathrm{G}$, and catalase $\mathrm{E}$ ) protected the E. coli cells against oxidative DNA damage and cell death.

There are two kinds of catalase (HPI and HPII), both of which can catalyze $\mathrm{H}_{2} \mathrm{O}_{2}$ into $\mathrm{H}_{2} \mathrm{O}$ and $\mathrm{O}_{2}$ in the wild type $E$. coli genome. HPI catalase is encoded by katG under OxyR control while HPII catalase is encoded by katE under KatF control (Loewen et al., 1985a, 1985b). Furthermore, HPI catalase can reduce the concentration of $\mathrm{H}_{2} \mathrm{O}_{2}$, while HPII catalase is not inducible by $\mathrm{H}_{2} \mathrm{O}_{2}$, but rather is regulated through a growth phase-dependent manner 

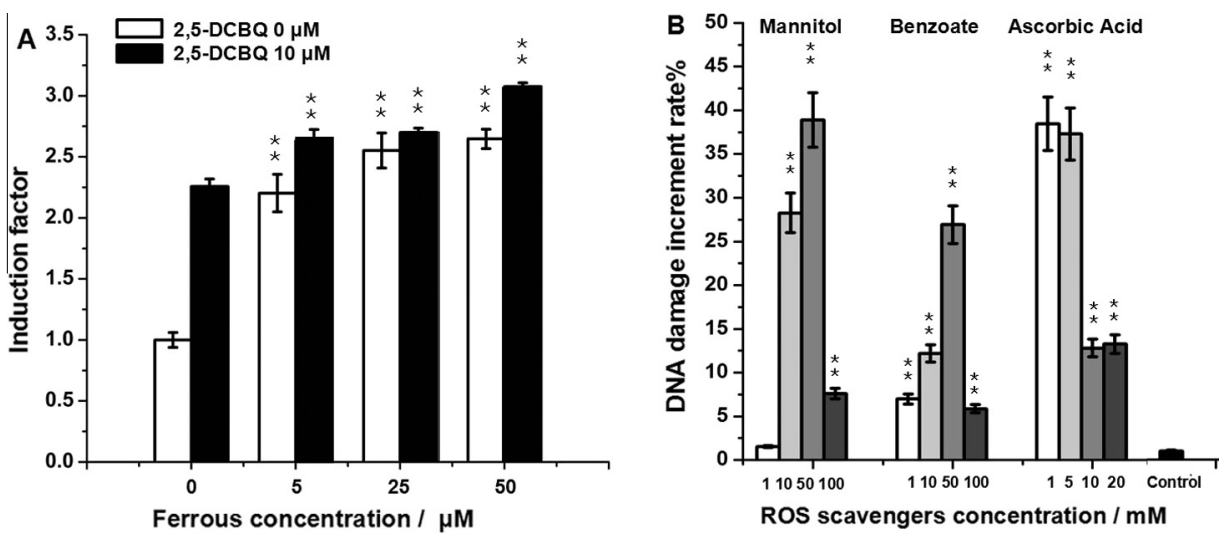

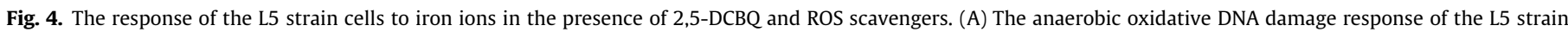

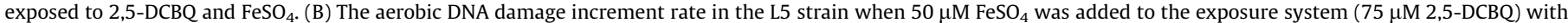

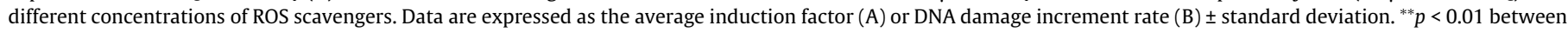
treatments and control.

Table 2

The response of the L5 strain cells under the exposure of 2,5-DCBQ and iron-chelators. ${ }^{1}$

\begin{tabular}{|c|c|c|c|c|c|c|c|}
\hline $\begin{array}{l}\text { 2,5-DCBQ concentration } \\
(\mu \mathrm{M})\end{array}$ & $\begin{array}{l}\text { Fe ions chelators } \\
\text { addition }\end{array}$ & $\begin{array}{l}\text { Induction } \\
\text { factor }\end{array}$ & $O D_{x} / O D_{0}$ & $\begin{array}{l}\text { 2,5-DCBQ concentration } \\
(\mu \mathrm{M})\end{array}$ & $\begin{array}{l}\text { Fe ions chelators } \\
\text { addition }\end{array}$ & $\begin{array}{l}\text { Induction } \\
\text { factor }\end{array}$ & $O D_{x} / O D_{0}$ \\
\hline 0 & - & $1.00 \pm 0.09^{a}$ & $1.00 \pm 0.01^{\mathrm{a}}$ & 100 & - & $4.55 \pm 0.43^{a}$ & $0.33 \pm 0.03^{\mathrm{a}}$ \\
\hline 0 & DFO & $1.74 \pm 0.20^{\mathrm{b}}$ & $0.57 \pm 0.01^{b}$ & 100 & DFO & $2.67 \pm 0.30^{\mathrm{b}}$ & $0.55 \pm 0.02^{b}$ \\
\hline 0 & DIP & $1.40 \pm 0.14^{\mathrm{a}}$ & $0.76 \pm 0.03^{c}$ & 100 & DIP & $3.27 \pm 0.20^{\mathrm{b}}$ & $0.66 \pm 0.04^{c}$ \\
\hline 0 & PHEN & $1.54 \pm 0.21^{\mathrm{a}}$ & $0.53 \pm 0.07^{b}$ & 100 & PHEN & $1.97 \pm 0.16^{c}$ & $0.44 \pm 0.02^{\mathrm{d}}$ \\
\hline
\end{tabular}

The L5 strain cells were exposed to a range of 2,5-DCBQ concentrations with or without DFO (2 mM), DIP (1 mM), or PHEN (2 mM).

${ }^{1}$ Values in the same column with different letters are significantly different as analyzed by Tukey's test $(p<0.01)$.
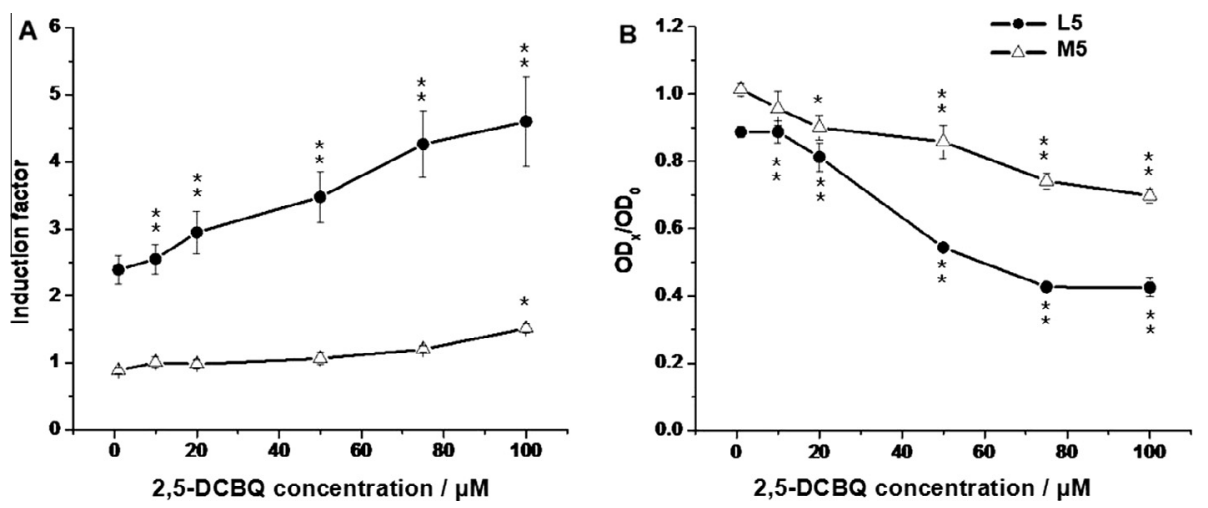

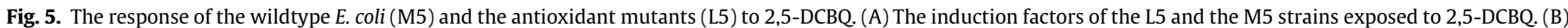

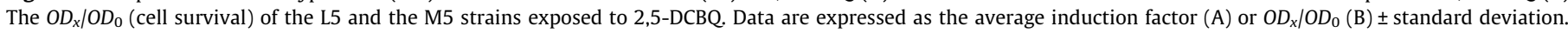
${ }^{* *} p<0.01$ or ${ }^{*} p<0.05$ between treatments and control.

(Farr and Kogoma, 1991; Schellhorn and Hassan, 1988). Another antioxidative enzyme found in the wild type $E$. coli genome is alkyl hydroperoxide reductase (Ahp), encoded by ahpCF. Ahp has been shown to provide additional defense to the cell by reducing the levels of either exogenous organic peroxides or peroxidized cellular components (Farr and Kogoma, 1991). Furthermore, E. coli ahpCF katEG cells under the exposure of oxygen produced submicromolar intracellular $\mathrm{H}_{2} \mathrm{O}_{2}$, which was then found to play a key role in cellular Fenton-like reactions that produce hydroxyl radicals (Park et al., 2005). Similarly, we found that both endogenous ROS (due to the mutation of ahpCF katEG, Fig. 5) and exogenous ROS (the addition of $\mathrm{H}_{2} \mathrm{O}_{2}$, Fig. 1) were able to enhance oxidative DNA damage. In addition, CBQs led to an increase of ROS, indicating that the toxicity of CBQs is facilitated by the participation of ROS in E. coli cells.
Previously, when the cytomembrane permeable $\mathrm{Fe}^{2+}$ chelator, PHEN (which has a similar chemical structure to DIP) was added to $E$. coli cultures prior to the addition of $\mathrm{H}_{2} \mathrm{O}_{2}$, the cells were protected from death (Asad et al., 1994). PHEN can quickly react with $\mathrm{Fe}^{2+}$ to form $\mathrm{Fe}^{2+}$-PHEN(I) and $\mathrm{Fe}^{2+}-\mathrm{PHEN}(\mathrm{II})$ complexes, and the two products (mono and bis complexes) can react with $\mathrm{H}_{2} \mathrm{O}_{2}$ to produce hydroxyl radicals. The $\mathrm{Fe}^{2+}$-PHEN(III) complex, which is the final and most stable product, is formed more slowly. Since DIP is a very similar compound to PHEN, we speculated that DIP would have the same reactions with $\mathrm{Fe}^{2+}$ and produce similar complexes. This protection would be due to the capture of $\mathrm{Fe}^{2+}$ ions leading the interruption of $\mathrm{Fe}^{2+}$-mediated $\mathrm{OH}$ production. Furthermore, another iron chelators, DFO, can permeate the cell membrane and form a non-reactive $\mathrm{Fe}^{3+}$-DFO complex and has also been found to protect pUC19 plasmid DNA against damage caused 
by the Fenton reaction, in vitro (Kim and Park, 2004) and inhibit $\mathrm{H}_{2} \mathrm{O}_{2}$-induced HL-60 leukemia cell death (Shim et al., 2003). DFO can effectively inhibit the formation of TCSQ; which was found to be produced following the exposure pure DNA (Zhu et al., 1998) and human fibroblasts (Witte et al., 2000) to tetrachlorohydroquinone (TCHQ), and to provide protection from DNA damage by chelating iron ions and directly interacting with TCHQ. As such, we speculate that the protective effect of DFO might not only be due to the chelation of $\mathrm{Fe}^{3+}$, but may also be due to direct interactions with $\mathrm{CBQs}$.

Nonetheless, the addition of iron chelators and ROS scavengers was not in a position to completely protect the $E$. coli cells from DNA damage and cell death (Fig. 3B and Table 2), indicating that CBQs may also cause DNA damage through other pathways. This result piqued our interest, pushing us to further our biochemical understanding of the mechanisms involved in HBQ-induced toxicity, in vitro. It has been proven that $\mathrm{CBQs}$ (such as 2-CBQ 2,5-DCBQ, and 2,6-DCBQ) directly react with dG and double-stranded DNA (calf thymus DNA) to form C8-dG O-adducts, in vitro (Dai et al., 2005). An additional study revealed that HBQs exhibit a capacity for binding to single- and double-stranded oligodeoxynucleotides to form $1: 1$ or $2: 1$ complexes through partial intercalation and H-bonding modes (Anichina et al., 2010). Organic hydroperoxides, such as tert-Butylhydroperoxide $(t-\mathrm{BuOOH})$ and cumene hydroperoxide $(\mathrm{CuOOH})$, were shown to nucleophilically attack CBQs in order to produce the respective organic alkoxyl radicals and $t$-BuO or $\mathrm{CuO}$ in a metal-independent manner, in vitro (Zhu et al., 2007). Moreover, subsequent research displayed that HBQs produce 8-oxo-7,8-dihydro-2'-deoxyguanosine (8-oxodG), a DNA oxidative damage marker, more efficiently in double-stranded DNA (calf thymus DNA) than in dG under the participation of $\mathrm{H}_{2} \mathrm{O}_{2}$ via not only a metal-independent but also an intercalation-enhanced oxidation mechanism (Yin et al., 2013). Finally, $\mathrm{H}_{2} \mathrm{O}_{2}$ has been shown to attack the nucleophile of TCBQ and form an unstable TriCBQ-OOH intermediate that decomposes homolytically through the cleavage of the $\mathrm{O}-\mathrm{O}$ bond to produce a hydroxyl radical with the assistance of water molecules (Zhu et al., 2007; Li et al., 2013). All these findings provide the possibility that the CBQ-induced DNA damage revealed in this study does not depend on iron, thus resulting in the partial maintenance of DNA when CBQ was added in the presence of iron chelators or ROS scavengers.

We also assume that, besides the above-mentioned in vitro mechanism, the addition of increasing levels of CBQs and intracellular $\mathrm{H}_{2} \mathrm{O}_{2}$ can result in a concurrent increase in ROS levels. Submicromolar levels of $\mathrm{H}_{2} \mathrm{O}_{2}$ in host LC106 cells has been shown to oxidize the $[4 \mathrm{Fe}-4 \mathrm{~S}]^{2+}$ cluster exposed to the aqueous phase of dehydratase families, thus creating an inactive $[3 \mathrm{Fe}-4 \mathrm{~S}]^{+}$cluster with the loss of one iron atom (Jang and Imlay, 2007). The released $\mathrm{Fe}^{3+}$ ion can react with cysteine or flavin within the cells to form ferrous ion (Woodmansee and Imlay, 2002; Park and Imlay, 2003). Reactions between ferrous ions and $\mathrm{H}_{2} \mathrm{O}_{2}$ produces the highly active hydroxyl free radical ${ }^{\circ} \mathrm{OH}$, which in turn can cause oxidative DNA damage. We hypothesize that $\cdot \mathrm{OH}$ attacks the $\mathrm{Fe}-\mathrm{S}$ proteins in the $\mathrm{L} 5$ strain and thus releases high concentrations of $\mathrm{Fe}^{2+}$ that can then participate in the intracellular Fenton-like reaction. This process would produce much more intracellular ROS in the L5 strain cells treated with CBQs than in the untreated L5 cells, demonstrating the magnified effect of the oxidative DNA damage.

\section{Conclusions}

In conclusion, we found that CBQs (BQ, 2-CBQ, 2,3-DCBQ, 2,5-DCBQ and 2,6-DCBQ) caused oxidative DNA damage in E. coli cells. CBQs were also able to enhance intracellular ROS levels; the addition of ROS scavengers partially protected the E. coli against DNA damage and cell death. Both the addition of endogenous and exogenous ROS led to oxidative DNA damage in E. coli cells exposed to CBQs; iron ions participated in this oxidative DNA damage process. Furthermore, iron chelators inhibited the production of oxidative DNA damage, while supplementing extra iron ions increased the level of oxidative DNA damage. Furthermore, antioxidative enzymes (Aph, catalase E, and catalase $\mathrm{G})$ protected the cells from oxidative DNA damage and cell death. Taken together, these findings suggest that iron-mediated ROS production plays an important role in CBQ-induced toxicity in E. coli cells.

\section{Acknowledgements}

We would like to thank Dr. Hailin Wang (Research Center for Eco-Environmental Sciences, CAS) for his kind financial support (National Natural Science Foundation of China (Grant Nos. 20737003, 21321004)) and Dr. James A. Imlay (University of Illinois) for his gift of the LC106 and MG1655 strains. Special acknowledgment goes to Dr. Mohammad Russel for his review and advice for improving this manuscript. We would also like to thank those peer reviewers who provided constructive suggestions and advice.

\section{References}

Anichina, J., Zhao, Y.L., Hrudey, S.E., Le, X.C., Li, X.F., 2010. Electrospray ionization mass spectrometry characterization of interactions of newly identified water disinfection byproducts halobenzoquinones with oligodeoxynucleotides. Environ. Sci. Technol. 44, 9557-9563.

Asad, N.R., Asad, L.M., Almeida, C.E., Leitão, A.C., 1994. Lethal interaction between hydrogen peroxide and o-phenanthroline in Escherichia coli. Braz. J. Med. Biol. Res. 27, 2551-2555.

Beckman, J.S., Siedow, J.N., 1985. Bactericidal agents generated by the peroxidasecatalyzed oxidation of para-hydroquinones. J. Biol. Chem. 260, 14604-146049.

Bull, R.J., Reckhow, D.A., Rotello, V., Bull, O.M., Kim, J., 2006. Use of Toxicological and Chemical Models to Prioritize DBP Research. American Water Works Association Research Foundation and American Water Works Association, Denver, CO.

Cantor, K.P., Lynch, C.F., Hildesheim, M.E., Dosemeci, M., Lubin, J., Alavanja, M., Craun, G., 1998. Drinking water source and chlorination byproducts. I. Risk of bladder cancer. Epidemiology 9, 21-28.

Chen, Z.L., Lu, M.L., Zhuang, G.Q., Wang, H.L., 2011. Enhanced bacterial biosensor for fast and sensitive detection of oxidatively DNA damaging agents. Anal. Chem. 83, 3248-3251.

Chen, Z.L., Lu, M.L., Zou, D.D., Wang, H.L., 2012. An E. coli SOS-EGFP biosensor for fast and sensitive detection of DNA damaging agents. J. Environ. Sci. - Chin. 24, $541-$ 549.

Chignell, C.F., Han, S.K. Mouithys-Mickalad, A, Sik, R.H., Stadler, K, Kadiiska, M.B. 2008. EPR studies of in vivo radical production by 3,3',5,5'-tetrabromobisphenol A (TBBPA) in the Sprague-Dawley rat. Toxicol. Appl. Pharmacol. 230, 17-22.

Dai, J., Sloat, A.L., Wright, M.W., Manderville, R.A., 2005. Role of phenoxyl radicals in DNA adduction by chlorophenol xenobiotics following peroxidase activation. Chem. Res. Toxicol. 18, 771-779.

Du, H., Li, J., Moe, B., McGuigan, C.F., Shen, S., Li, X.F., 2013. Cytotoxicity and oxidative damage induced by halobenzoquinones to T24 bladder cancer cells. Environ. Sci. Technol. 47, 2823-2830.

Farr, S.B., Kogoma, T., 1991. Oxidative stress responses in Escherichia coli and Salmonella typhimurium. Microbiol. Rev. 55, 561-585.

Greenberg, J.T., Demple, B., 1989. A global response induced in Escherichia coli by redox-cycling agents overlaps with that induced by peroxide stress. J. Bacteriol. $171,3933-3939$.

Gunther, M.R., Hanna, P.M., Mason, R.P., Cohen, M.S., 1995. Hydroxyl radical formation from cuprous ion and hydrogen peroxide: a spin-trapping study. Arch. Biochem. Biophys. 316, 515-522.

Gupta, S.S., Stadler, M., Noser, C.A., Ghosh, A., Steinhoff, B., Lenoir, D., Horwitz, C.P., Schramm, K.W., Collins, T.J., 2002. Rapid total destruction of chlorophenols by activated hydrogen peroxide. Science 296, 326-328.

Heasley, V.L., Fisher, A.M., Herman, E.E., Jacobsen, F.E., Miller, E.W., Ramirez, A.M., Royer, N.R., Whisenand, J.M., Zoetewey, D.L., Shellhamer, D.F., 2004 Investigations of the reactions of monochloramine and dichloramine with selected phenols: examination of humic acid models and water contaminants. Environ. Sci. Technol. 38, 5022-5029.

Henle, E.S., Luo, Y., Gassmann, W., Linn, S., 1996. Oxidative damage to DNA constituents by iron-mediated Fenton reactions. The deoxyguanosine family. J. Biol. Chem. 271, 21177-21186. 
Huang, R.F., Wang, W., Qian, Y.C., Boyd, J.M., Zhao, Y.L., Li, X.F., 2013. Ultra pressure liquid chromatography-negative electrospray ionization mass spectrometry determination of twelve halobenzoquinones at $\mathrm{ng} / \mathrm{l}$ levels in drinking water. Anal. Chem. 85, 4520-4529.

Imlay, J.A. 2003. Pathways of oxidative damage. Annu. Rev. Microbiol. 57, 395-418.

Jang, S., Imlay, J.A., 2007. Micromolar intracellular hydrogen peroxide disrupts metabolism by damaging iron-sulfur enzymes. J. Biol. Chem. 282, 929-937.

Kim, Y.G., Park, H.Y., 2004. The effects of Pycnogenol on DNA damage in vitro and expression of superoxide dismutase and HP1 in Escherichia coli SOD and catalase deficient mutant cells. Phytother. Res. 18, 900-905.

King, W.D., Marrett, L.D., 1996. Case-control study of bladder cancer and chlorination by-products in treated water (Ontario, Canada). Cancer Causes Control 7, 596-604.

Li, P., Wang, W., Sun, Q., Li, Z., Du, A., Bi, S., Zhao, Y., 2013. Insights into the mechanism of the reaction between tetrachloro-p-benzoquinone and hydrogen peroxide and their implications in the catalytic role of water molecules in producing the hydroxyl radial. ChemPhysChem 14, 2737-2743.

Lloyd, D.R., Phillips, D.H., 1999. Oxidative DNA damage mediated by copper(II), iron(II) and nickel(II) fenton reactions: evidence for site-specific mechanisms in the formation of double-strand breaks, 8-hydroxydeoxyguanosine and putative intrastrand cross-links. Mutat. Res. 424, 23-36.

Loewen, P.C., Switala, J., Triggs-Raine, B.L., 1985a. Catalases HPI and HPII in Escherichia coli are induced independently. Arch. Biochem. Biophys. 243, 144149.

Loewen, P.C., Triggs-Raine, B.L., George, C.S., et al., 1985b. Genetic mapping of katG, a locus that affects synthesis of the bifunctional catalase-peroxidase hydroperoxidase I in Escherichia coli. J. Bacteriol. 162, 661-667.

Macomber, L., Rensing, C., Imlay, J.A., 2007. Intracellular copper does not catalyze the formation of oxidative DNA damage in Escherichia coli. J. Bacteriol. 189, 1616-1626.

McCarthy, D.L., Claude, A.A., Copley, S.D., 1997. In vivo levels of chlorinated hydroquinones in a pentachlorophenol-degrading bacterium. Appl. Environ. Microbiol. 63, 1883-1888.

Mccormick, M.L., Buettner, G.R., Britigan, B.E., 1998. Endogenous superoxide dismutase levels regulate iron-dependent hydroxyl radical formation in Escherichia coli exposed to hydrogen peroxide. J. Bacteriol. 180, 622-625.

McGeehin, M.A., Reif, J.S., Becher, J.C., Mangione, E.J., 1993. Case-control study of bladder cancer and water disinfection methods in Colorado. Am. J. Epidemiol. 138, 492-501.

Meunier, B., 2002. Catalytic degradation of chlorinated phenols. Science 296, 270 271.

Oikawa, S., Kawanishi, S., 1996. Copper-mediated DNA damage by metabolites of pdichlorobenzene. Carcinogenesis 17, 2733-2739.

Park, S., Imlay, J.A., 2003. High levels of intracellular cysteine promote oxidative DNA damage by driving the fenton reaction. J. Bacteriol. 185, 1942-1950.

Park, S., You, X.J., Imlay, J.A., 2005. Substantial DNA damage from submicromolar intracellular hydrogen peroxide detected in Hpx-mutants of Escherichia coli. Proc. Natl. Acad. Sci. U.S.A. 102, 9317-9322.
Qian, Y.C., Wang, W., Boyd, J.M., Wu, M.H., Hrudey, S.E., Li, X.F., 2013. UV-induced transformation of four halobenzoquinones in drinking water. Environ. Sci. Technol. 47, 4426-4433.

Sambrook, J., Russell, D.W., 2001. Molecular Cloning: A Laboratory Manual, third ed. Cold Spring Harbor Press, Cold Spring Harbor, NY.

Schellhorn, H.E., Hassan, H.M., 1988. Response of hydroperoxidase and superoxide dismutase deficient mutants of Escherichia coli K-12 to oxidative stress. Can. J. Microbiol. 34, 1171-1176.

Shim, H.W., Moon, M.S., Shin, K.S., Cho, H.J., Yoo, B.S., Kim, I.G., 2003. Alphadifluoromethylornithine, ornithine decarboxylase inhibitor, antagonizes $\mathrm{H}_{2} \mathrm{O}_{2}-$ induced cytotoxicity in HL-60 leukemia cells: regulation of iron-dependent lysosomal damage. Cell Biol. Toxicol. 19, 393-405.

Song, Y., Wagner, B.A., Lehmler, H.J., Buettner, G.R., 2008. Semiquinone radicals from oxygenated polychlorinated biphenyls: electron paramagnetic resonance studies. Chem. Res. Toxicol. 21, 1359-1367.

Sorokin, A., Meunier, B., Séris, J.L., 1995. Efficient oxidative dechlorination and aromatic ring cleavage of chlorinated phenols catalyzed by iron sulfophthalocyanine. Science 268, 1163-1166.

Van Bogelen, R.A., Kelley, P.M., Neidhardt, F.C., 1987. Differential induction of heat shock, SOS, and oxidative stress regulons and accumulation of nucleotides in Escherichia coli. J. Bacteriol. 169, 26-32.

Villanueva, C.M., Cantor, K.P., Cordier, S., Jaakkola, J.J., King, W.D., Lynch, C.F., Porru, S., Kogevinas, M., 2004. Disinfection byproducts and bladder cancer: a pooled analysis. Epidemiology 15, 357-367.

Wang, W., Qian, Y.C., Boyd, J.M., Wu, M.H., Hrudey, S.E., Li, X.F., 2013 Halobenzoquinones in swimming pool waters and their formation from personal care products. Environ. Sci. Technol. 47, 3275-3282.

Witte, I., Zhu, B.Z., Lueken, A., Magnani, D., Stossberg, H., Chevion, M., 2000. Protection by desferrioxamine and other hydroxamic acids against tetrachlorohydroquinone-induced cyto- and genotoxicity in human fibroblasts. Free Radic. Biol. Med. 28, 693-700.

Woodmansee, A.N., Imlay, J.A., 2002. Reduced flavins promote oxidative DNA damage in non-respiring Escherichia coli by delivering electrons to intracellular free iron. J. Biol. Chem. 277, 34055-34066.

Yin, R.C., Zhang, D.P., Song, Y.L., Zhu, B.Z., Wang, H.L., 2013. Potent DNA damage by polyhalogenated quinones and $\mathrm{H}_{2} \mathrm{O}_{2}$ via a metal-independent and intercalation-enhanced oxidation mechanism. Sci. Rep. 3, 1269.

Zhao, Y.L., Qin, F., Boyd, J.M., Anichina, J., Li, X.F., 2010. Characterization and determination of chloro- and bromo-benzoquinones as new chlorination disinfection byproducts in drinking water. Anal. Chem. 82, 4599-4605.

Zhu, B.Z., 2009. A novel mechanism for metal-independent production of hydroxyl radicals. Chin. Sci. Bull. (Chin. Ver.) 54, 1673-1680 (in Chinese).

Zhu, B.Z., Har-El, R., Kitrossky, N., Chevion, M., 1998. New modes of action of desferrioxamine: scavenging of semiquinone radical and stimulation of hydrolysis of tetrachlorohydroquinone. Free Radic. Biol. Med. 24, 360-369.

Zhu, B.Z., Zhao, H.T., Kalyanaraman, B., Liu, J., Shan, G.Q., Du, Y.G., Frei, B., 2007 Mechanism of metal-independent decomposition of organic hydroperoxides and formation of alkoxyl radicals by halogenated quinines. Proc. Natl. Acad. Sci. U.S.A. 104, 3698-3702. 